\title{
MOBILE TECHNOLOGY: PLUGGED IN AND ALWAYS ON
}

\author{
Karen L. Paullet, Robert Morris University, paullet@rmu.edu \\ Jamie L. Pinchot, Robert Morris University, pinchot@rmu.edu \\ David Douglas, Robert Morris University, dmdst27@mail.rmu.edu \\ Daniel R. Rota, Robert Morris University, rota@rmu.edu
}

\begin{abstract}
We are living in a world where people are staying connected via mobile technology more than ever. People are "plugged-in" and connected to what has become an "always on" world. Technology which was once only found on desktop computers can now be carried in the palm of our hands. Mobile devices such as smart phones allow people to have a constant connection to friends, family, and information. This exploratory study of 168 undergraduate and graduate students at a mid-Atlantic university examines the growing dependency students have on mobile technology. Findings indicate that students rely on mobile technology to fulfill their primary communication and information seeking needs.
\end{abstract}

Key words: mobile communication, mobile devices, cell phone, mobile phone, texting, technology dependency, communication

\section{INTRODUCTION}

We are living in a world where people are staying connected via mobile technology more than ever before. People are staying "plugged-in" and connected to what has become an "always on" world. Technology which was once only found on desktop computers can now be carried in the palm of our hands. Mobile devices allow people to have a constant connection to friends, family, and information.

Although the commercial application of mobile phone technology is less than 30 years old, its swift ascent to the top of the telecommunication food chain is both astounding and unprecedented. No other technology or invention has been globally embraced so quickly and adopted so easily in all of recorded history regardless of culture or generation.

Edward Hallowell in his book Crazy Busy [7] tells a story about being on vacation at a lakeside cottage with his family. Due to the remote location of the cottage the family had to rely on an old rotary phone since mobile phone coverage was not available. Hallowell wanted to call a neighbor to invite him to a baseball game. He picked up the rotary phone and started dialing the neighbor's number. Hallowell became impatient as he had to wait for each number to swing back on the rotary phone. In his mind he was thinking that he could have dialed the entire number with one button on his mobile phone. After the neighbor answered the phone Hallowell decided to redial the number on the rotary phone to see how long it actually took to make the phone call. To his surprise it only took 11 seconds. The point of providing this analogy is to show how dependent we have become on the mobile technology that surrounds us. To think that 11 seconds seemed like an eternity is almost ludicrous. Are we becoming a culture that depends on mobile technology for all facets of daily living?

\section{LITERATURE REVIEW}

The first commercial mobile phone call was placed from Soldier Field in Chicago on October 13, 1983. From that one call, the commercial wireless industry was formally launched [3]. As of July 2010, there were over five billion mobile phone connections worldwide. The penetration in some regions exceeds 100 percent because some people have more than one mobile phone. There have been over 10 billion mobile phones sold worldwide since 1994 [2].

A 2010 study by Junco and Mastrodicasa [9] that surveyed 7,705 U.S. college students found that $94 \%$ of students own a mobile phone. The study also found that the Millennial generation, which includes people born between the 
years 1977 and 1994 [6], may have learned to communicate primarily through the use of technology. The Millennial generation accounts for the majority of students attending college in 2011.

Hemmer [8] used focus groups to determine the impact of text messaging on communication. The study sought to answer questions such as "Do you think text messaging displaces face-to-face communication?" Both male and female focus groups divulged that they use text messaging to avoid face-to-face communication.

Mobile phones provide many conveniences, including the ability to make use of time previously wasted. People can now send text messages, check their email, update social networking sites, or browse web sites while waiting in line at the grocery store, or sitting in the waiting room at a doctor's appointment. This spare time can now be made useful, spent in communicating with others, performing tasks online, or simply gathering information [10].

People are increasingly aware of the concept that a phone number is connected directly to a person, rather than to a place. This has led to a major shift in expectations regarding how people contact one another. It is increasingly expected that a person answer a mobile phone call or message, regardless of time, place, or activity [15].

A 2010 Pew Internet study [12] of 2,252 American adults sought to determine if adults were being distracted by mobile phones. The study revealed that $47 \%$ of adults have sent or read text messages while driving. Additionally, $75 \%$ of adults admitted to talking on their mobile phones while driving. An alarming $44 \%$ of adults surveyed say they have been in a car when the driver used a mobile phone in a way that put them in danger. The study revealed that $51 \%$ of males compared to $42 \%$ of females reported texting while driving. Additionally, those surveyed between the ages of 18-33 are more likely to report texting while driving than any other age. The older the participant the less likely they were to report texting while driving.

Those in the Millennial generation (ages 18-33) are more likely than any other group to report texting while driving. While $59 \%$ of texting Millennial students report sending or reading messages at the wheel, $50 \%$ of text-using Gen Xers (ages 34-45) and 29\% of texting Baby Boomers (ages 46-64) report the same [12].

Harris Interactive conducted a recent study of 1,012 U.S. adults in August of 2010 on how to keep Internet security simple. The results of the study revealed that staying connected is a very serious issue for many people. More Americans are staying "plugged-in" no matter what the circumstances are surrounding the situation. For instance, the study revealed that $29 \%$ of those surveyed believe that they should be "plugged-in" on their honeymoon; while $41 \%$ believe it is acceptable to have mobile devices at the dinner table [14].

According to a recent survey of 600 students (ages 13 to 17) conducted by textPlus, $42 \%$ of teens admit to texting during class. Almost $80 \%$ of students reported that they have never gotten in trouble at school for texting during class. Teachers have enough trouble keeping their students attention as it is without the distraction from mobile devices. The study showed that a staggering $66 \%$ of students reported receiving texts from their parents during class time. It is no surprise then to learn that $74 \%$ of students answered "no" when asked if they thought it was wrong to text in class [5].

A 2010 study conducted by Paullet, et. al. [13], sought to determine if students are becoming increasingly dependent on technology. Eighty-eight students were asked if they could spend an entire day without the use of computers or mobile devices. The study revealed that $60 \%$ of the students could not spend an entire day without the use of technology devices. Additionally, 54\% of students would feel panicked or upset if technology failed and they could not be reached.

\section{PURPOSE OF STUDY}

Prior studies have found that students are increasingly dependent upon mobile technology devices. Cultural preferences and behaviors for all types of communication are affected by this dependence [13, 15]. Clear boundary lines have not been set regarding socially acceptable behaviors for the use of mobile devices in a culture where everyone is increasingly plugged in to their digital communication networks. 
Volume XII, No. 1, pp. 141-150, 2011

The purpose of this study is to determine how dependent students are on mobile technology and to identify their preferences and boundaries regarding its use.

This study explores the following research questions:

RQ1: Are mobile devices the preferred method of communication for university students?

RQ2: Are university students dependent on mobile technology to fulfill their primary communication needs?

\section{METHODOLOGY}

This study examined mobile device dependency of undergraduate and graduate students ages 18 or older at a midAtlantic university. The researchers selected a quantitative methodology and designed the survey as an extension of their 2010 survey of technology dependency but narrowing the focus to specifically address mobile technology dependence [13]. The survey was developed for a 2010 study. Based on the results from the original study the authors added a section to focus on a variety of mobile devices in addition to mobile phones.

The survey questions focused on querying students regarding their dependency on mobile devices and their preferences for usage of mobile devices. The survey questionnaire was a four-page document consisting of 31 questions. The first section of the survey gathered participant demographics including gender, age, and the school within the university in which the student was enrolled. The school was important to researchers to ensure that an adequate cross section of majors and disciplines were represented in the sample. This had been a limitation in the 2010 study [13]. The second section of the survey focused on the students' use of phones, including number of mobile and landline phones owned and used, texting habits, and communication preferences. The third section of the survey asked students to identify the mobile devices that they own from a list of common devices such as mobile phone, laptop, Kindle/eBook reader, iPad, and others. Preferences regarding the use of the owned devices were then addressed. The fourth and final section of the survey addressed the students' reliance on mobile devices.

\section{Sample}

The sample consisted of 168 undergraduate and graduate students at a mid-Atlantic university. A convenience sample was used with a 5\% margin of error and a 95\% confidence level. The researchers administered the survey to students in five schools within the university in March 2011, including: School of Communications and Information Systems, School of Education and Social Sciences, School of Engineering, Mathematics, and Science, and School of Nursing. All participants were informed that the survey was strictly voluntary and would not impact their current or future relations with the university.

\section{RESULTS}

This study sought to identify the extent to which university students have become dependent on mobile devices. The survey requested participants to indicate their gender, age, and school within the university. Results found that the male and female genders were not represented equally in the participant sample. Over half of participants were male, 68\% (114), with 32\% (54) female. Of the 168 participants, 132 students were between the ages of 18-33 (Millennials), 25 were ages 34-45 (Generation X), and 11 were ages 46-64 (Baby Boomers). Just over half of the students, 55\% (93), were enrolled in the School of Communications and Information Systems. The School of Business had 38\% (64) participants. The remaining 7\% (11) of student participants came from the School Education and Social Sciences, the School of Engineering, Mathematics and Science, and the School of Nursing.

Research Question 1 sought to determine if students prefer mobile devices for communication. All 168 students that completed the survey responded that they have and use at least one mobile phone. A majority of the participants, $96 \%$, indicated that they receive the majority of their phone calls on a mobile phone. Four percent indicated that they receive the majority of their calls on a land line. Over half of the participants, $60 \%$, responded that their household did have a land line, and $40 \%$ responded that there was no land line in their household. 
Volume XII, No. 1, pp. 141-150, 2011

Survey questions addressed how and why students use text messaging. The majority of students, 95\%, responded that they use text messaging as a form of communication. Students were asked how many text messages they sent and received daily. The responses varied from 0 to 750 (per day) in both sending and receiving categories. The average number of text messages sent per day was 49 (median 20), and the average number of text messages received per day was 57 (median 20).

Over half of the research participants, $60 \%$, responded that they prefer texting to making a phone call. There is a statistically significant relationship between age and whether texting is preferred to making a phone call (chi-square $=13.904, d f=2, \mathrm{p}<.001)$. Younger students, ages 18-33, are more likely to prefer texting to making a phone call.

A 2009 study by Hemmer [8] found that participants believed that text messaging is used to avoid face-to-face communication. This study addressed the same topic by asking students if they use text messaging to avoid face-toface communication. The majority of students, $73 \%$, said they did not. Approximately $27 \%$ of the students responded that they did use text messaging to avoid face-to-face communication. When asked if they use text messaging to avoid voice-to-voice communication, over half of the students, $60 \%$, responded they did not, while $40 \%$ said they did use text messaging to avoid voice-to-voice communication.

When asked how they communicate most often, $48 \%$ of the students responded that they use texting as their most frequent communication method. Approximately $35 \%$ of students responded that they talk on a mobile phone most often. Nine percent of students indicated email as their preferred communication method, $3 \%$ indicated online chat, $2 \%$ indicated social network sites, and $2 \%$ indicated talking on a land line. Between texting and talking on a mobile phone, results clearly show that the majority of students, $83 \%$, use a mobile phone as their primary communication method. A strong statistically significant relationship was also found between age and the method for communicating most often (chi-square $=37.451, d f=12, \mathrm{p}<.000$ ). Younger students in the Millennial age group were more likely to communicate most often by text messaging and talking on a mobile phone.

Research Question 2 sought to determine if students depend on mobile technology to fulfill their primary communication needs. A series of survey questions were asked in order to address this question. Participants were asked if they consider themselves to be addicted to mobile phone technology or texting. Just over half of the students, $52 \%$, responded that they were addicted to mobile phone technology, as shown in Figure 1 . Thirty-one percent (31\%) of the students responded that they were addicted to texting. A statistically significant relationship was found between age and mobile phone addiction (chi-square $=6.481, d f=2, \mathrm{p}<.05$ ). Students in the Millennial age group were more likely to report being addicted to mobile phone technology. 
Volume XII, No. 1, pp. 141-150, 2011

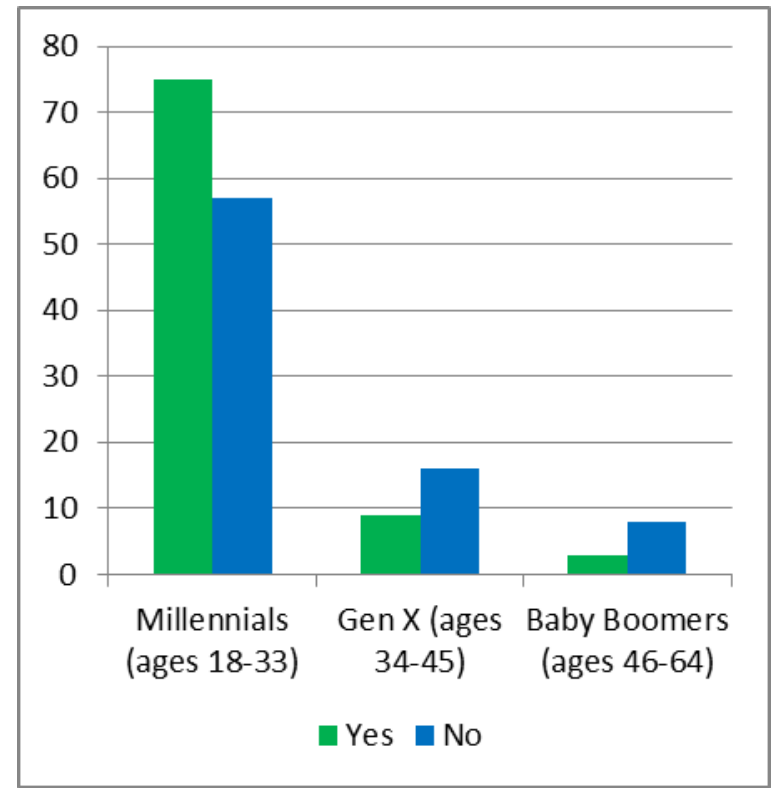

Figure 1 - Number of students who responded if they were addicted to mobile phone technology, by age.

Approximately $66 \%$ of the students indicated that they would feel panicked or upset if they left their phone behind for the day, and the majority of students, $78 \%$, responded that they have gone back to pick up their phone when it was left behind.

The majority of participants, 87\%, indicated that they keep at least one mobile device by their bed side. Approximately $46 \%$ of the students responded that they would answer a text message if it woke them up at night, and $72 \%$ responded that they check their mobile device in the morning before they even get out of bed. The study revealed a strong statistically significant relationship between age and keeping a mobile device by the bed side (chisquare $=15.364, d f=2, \mathrm{p}<.000$ ). It also revealed a strong statistical relationship between age and checking a mobile device in the morning before getting out of bed (chi-square $=18.988, d f=2, \mathrm{p}<.000$ ), as shown in Figure 2 .

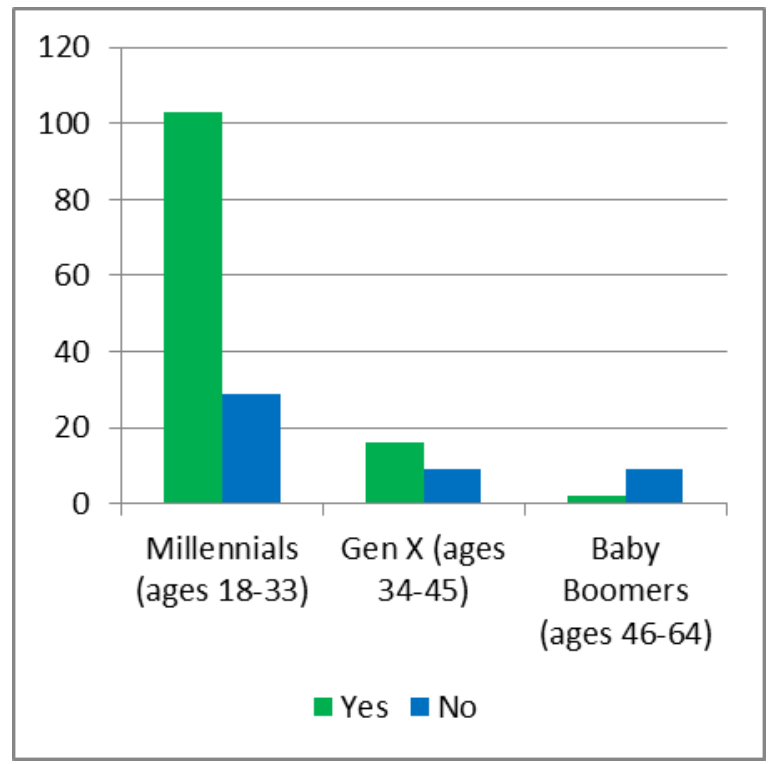


Volume XII, No. 1, pp. 141-150, 2011

Figure 2 - Number of students who responded if they check their mobile device before getting out of bed in the morning, by age.

In addition, a statistically significant relationship was found between age and answering a text in the night if it woke the student up (chi-square $=8.755, d f=2, \mathrm{p}<.01$ ). Together, these findings indicate that students in the younger Millennial age group are more likely to report activities related to mobile device dependency such as keeping a mobile device near them while sleeping, answering text messages regardless of time of night, and checking mobile devices in the morning even before getting out of bed.

As an additional indicator of dependence on mobile devices, research participants were asked if they talk on their mobile phone while driving. Approximately $84 \%$ of respondents reported talking on their mobile phones while driving, with $51 \%$ of students indicating that they text while driving. There is a statistically significant relationship between gender and texting while driving (chi-square $=6.380, d f=1, \mathrm{p}<.01$ ).

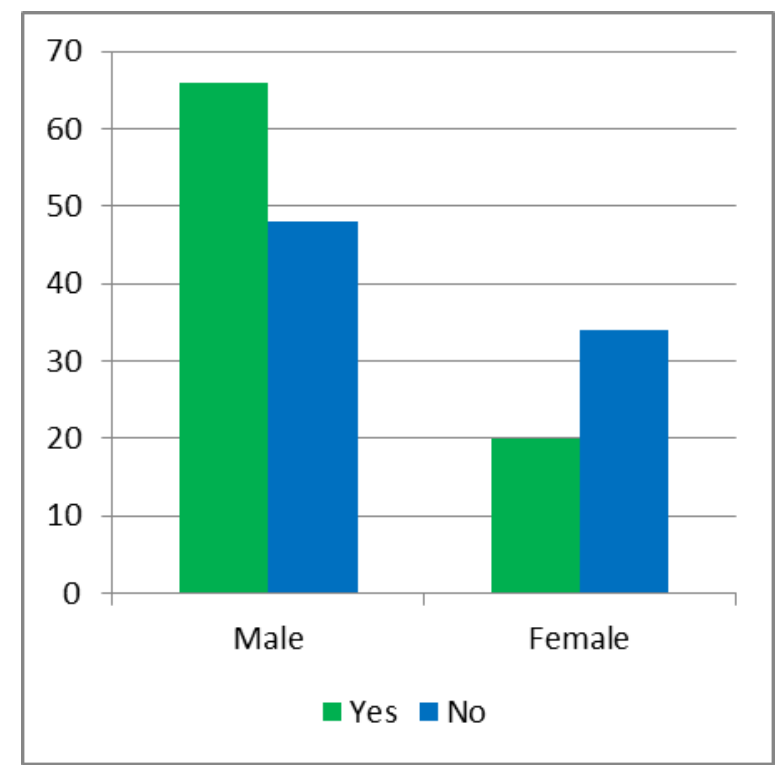

Figure 3 - Number of students who responded if they text while driving, by gender.

Approximately $77 \%$ of males reported texting while driving compared to $23 \%$ of females, as shown in Figure 3. 
Volume XII, No. 1, pp. 141-150, 2011

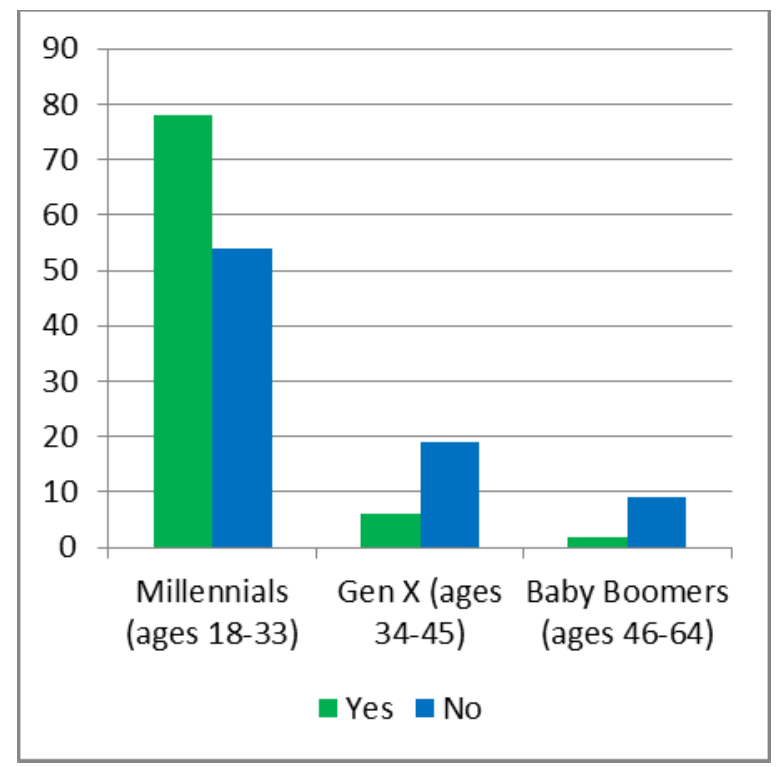

Figure 4 - Number of students who responded if they text while driving, by age.

There is also a strong statistically significant relationship between age and texting while driving (chi-square $=$ 15.492, $d f=2, \mathrm{p}<.000$ ), shown in Figure 4. As a student's age progresses, the less likely they are to report texting while driving.

\section{DISCUSSION}

The use of mobile devices has become an acceptable and common practice which people have become accustomed to for not only communication but also to complete their daily activities. This study sought to determine how students have become dependent on mobile technology and to identify their preferences and boundaries regarding its use.

The results of this study show that the number of students who said they prefer texting to making a phone call increased from 53\% in 2010 to $60 \%$ in 2011 [15]. Students reported sending and receiving 0 to 750 text messages per day in the current study. The number of text messages sent in the 2011 study versus the 2010 study by the same researchers has also increased dramatically. The average number of texts sent per day in 2010 was 22 . The average number of text messages sent per day in 2011 was 49 and the average number of text messages received was 57 [15]. The increase in the use of texting from 2010 to 2011 may be an indication that people prefer this form communication to avoid face-to-face communication.

A 2010 Pew study [12] surveyed over 2,000 adults ages 18 and older. The study found that $47 \%$ of texting adults say they have either sent or read text messages while driving. Approximately $75 \%$ said they have talked on the phone while driving. Almost 50\% reported having watched another driver talk or text while they were a passenger in a vehicle, and $47 \%$ said they have been in a car where the driver put them in danger by using a mobile phone while driving. This study found that $84 \%$ of students reported talking on their mobile phones while driving, and $51 \%$ indicated that they text while driving, supporting the findings of the Pew study. In addition, the Pew study [12] found that male texters are more likely to report texting at the wheel, with 51\% indicating that they have read or sent text messages while driving, compared to $42 \%$ females. This study found a similar result, with approximately $77 \%$ of males reporting texting while driving, compared to only $23 \%$ of females. The Pew study [12] also found that Millennial students are more likely to report texting while driving. Again this study supported the findings from Pew, showing that over $90 \%$ of Millennials reported texting while driving. 
With the growth of mobile technology and the Internet, there is always a continual presence that makes people want to stay in touch with one another. The Internet, cell phone and other mobile technologies have freed us from geographic constraints and permit us to stay connected to anyone in the world.

The first research question sought to determine if mobile devices are the preferred method of communication for university students. A majority of students, $60 \%$, prefer texting than talking on the phone. Additionally, $48 \%$ of students reported texting as their primary form of communication followed by $35 \%$ who prefer talking on their mobile phone. The combined percentage of students that use a form of mobile technology as their primary form of communication is $83 \%$.

Text messaging is rapidly becoming more popular than voice conversations [13]. People find the ease of sending short messages to be more convenient and effective at conveying information and receiving quick answers to questions. This medium allows a person to engage in short bursts of communication without engaging in a more extended conversation. It also extends the level of informality. Text messaging, by nature, is meant to be short. This limitation on the number of characters for each message allows people to forego the greetings, formalities, and "small talk" that typically must occur if you send an email or have a voice conversation. Instead the text message gets straight to the point.

The second research question examined whether or not university students are dependent on mobile technology to fulfill their primary communication needs. Based on the statistics of the study, 52\% of students reported being addicted to mobile phone technology while $31 \%$ admitted to being addicted to texting. Once again, the Millennial generation which has grown up surrounded by technology surpasses both Gen X and the Baby Boomer respondents.

In performing this research to determine whether or not students have become dependent on mobile technology, the researchers found that $66 \%$ of participants would feel panicked or upset if they left their phone behind. To further prove dependency on mobile technology, $87 \%$ of participants keep a mobile device by their bedside at night. Almost half of the survey participants answer a text message through the night. Additionally, $72 \%$ of students check their mobile devices for messages before they get out of bed in the morning. Students have indicated that their mobile devices have taken the place of their land line phone, alarm clock, GPS, camera, and more.

Mobile phones and other wireless devices are already transforming well-established communication patterns. A single smart phone can now replace many formerly independent forms of communication. Mobile phones can be used to send text messages, send emails, and update social networking sites, as well as making voice calls. The mediums for any type of message are available through one device. In addition, the mobile phone can also use a variety of applications to replace the functions of many other previously separate devices, including an alarm clock, camera, video camera, MP3 music player, e-book reader, clock, calculator, compass, GPS device, and more. This all-in-one feature set makes the mobile phone the most important communication device that most people own. This can lead to dependence and personal attachment to the device, so much that many people admit to feeling lost without their mobile phone. Mobile phones are becoming so addictive that a 2010 survey found that 8 out of 10 business professionals would rather give up coffee than their mobile phone [4]. Additionally a 2010 study conducted by PC Tools [14] showed that $29 \%$ of Americans think that is acceptable to be plugged in on their honeymoon. The constant desire to stay connected by mobile technology shows that it is becoming a socially acceptable practice.

\section{LIMITATIONS}

Demographic results revealed that male participants outnumbered female participants. This could have been attributed to conducting the survey using a majority of students from the School of Communications and Information Systems in which the majority of the students are male. Care was taken to include participants from other schools, but over half of the research participants were from this school. Future research could compare populations of students from other regions of the country. 
Volume XII, No. 1, pp. 141-150, 2011

\section{CONCLUSION}

The need for humans to communicate is real and deeply rooted in our origins as humans. The "always-on" culture and the "plugged-in" world of mobile technology in the twenty-first century has made a lasting and deep impression on both our individual psyche and our global culture.

It is not difficult to see the plethora of people who have mobile communication devices in 2011. Women, men, and children all seem to have that ubiquitous appendage in their hand texting or in their ear talking. Likewise, the generational and cultural disparity is rapidly diminishing, as the world has appeared to embrace and become dependent on mobile technology and it's rapidly evolving technological marvels.

Our sample shows that the younger generation of "Millennials" is more likely to admit addiction to mobile technology and other mobile-dependent behaviors than their older counterparts. However, the use of mobile devices for talking, texting, and other information-gathering tasks is clearly on the rise amongst all age groups.

Statistical conclusions from the participants of this specific study revealed that 52\% of the respondents considered themselves to be addicted to mobile phone technology and 31\% considered themselves addicted to texting. Eightyone (81\%) percent of the respondents said that they kept at least one mobile device by their bedside, and an astonishing $72 \%$ reported that they check their mobile device in the morning before even getting out of bed. These findings clearly indicate a growing trend toward dependence on mobile technology, and perhaps, for some, addiction to it.

Future studies should focus on the habits and preferences of mobile device users. In particular, talking and texting while driving should be analyzed more thoroughly, as distracted driving could be an extremely dangerous consequence of mobile device dependency.

\section{REFERENCES}

1. Alexander, E., Ward, C. B., \& Braun, C. K. (2007). Cell phone attachment: A measure and its benefits. In PROCEEDINGS of the IABE-2007 Annual Conference. Symposium conducted at Las Vegas, NV. Retrieved from http://www.iabe.eu/domains/iabe/Documents/Proceedings/IABE-2007\%20Proceedings.pdf\#page=417

2. Anonymous, BBC new technology, 2010. Over 5 billion mobile phone connections worldwide. Retrieved on March 27, 2011 from http://www.bbc.co.uk/news/10569081/

3. Anonymous. (2011). CITA Consumer Info. Top ten wireless moments. Retrieved on March 24, 2011 from http://www.ctia.org/consumer_info/top_ten/

4. Bradley, T. (2010, April 13). Business professionals choose smartphones over coffee. PC World. Retrieved from http://www.pcworld.com/businesscenter/article/194137/Busi-

ness_professionals_choose_smartphones_over_coffee.html

5. Carr, A. (2010, September 8). Who's that texting your kids in class $66 \%$ of the time? Parents. FastCompany.com. Retrieved on March 29, 2011 from http://www.fastcompany.com/node/1687648/print/

6. CRM Trends (2010). Evolving consumer demographics. Retrieved on January 23, 2010 from http://www.crmtrends.com/consumerdemographics.htm

7. Hallowell, E.M. (2007). Crazy Busy: Overstretched, overbooked and about to snap! Strategies for coping in a world gone ADD. The Random Publishing House, Inc: New York

8. Hemmer, H. (2009). Impact of text messaging on communication. Journal of Undergraduate Research at the Minnesota State University. 


\section{Issues in Information Systems}

Volume XII, No. 1, pp. 141-150, 2011

9. Junco, R. \& Mastrodicasa, J. (2007). Connecting to the net generation. NASPA

10. Katz, J. E., \& Aakhus, M. A. (Eds.). (2002). Perpetual contact: mobile communication, private talk, public performance. Cambridge: Cambridge University Press.

11. Kopomaa, T. (2000). The City in Your Pocket. Birth of the Mobile Information Society. Helsinki: University Press Finland.

12. Madden, M., \& Rainie, L. (2010, June 18). Adults and Cell Phone Distractions, Pew Internet and American Life Project. Pew Research Center. Retrieved on 4/29/10 from http://pewinternet.org/reports/2010/cell-phonedistractions.aspx

13. Paullet, K. L., Pinchot, J. L., \& Rota, D. R. (2010). Technology: Convenience or necessity. Issues in Information Systems, XI(1), pp. 439-444.

14. PC Tools (2010, September 16). PCTools poll reveals surprising attitudes on when it is ok to be 'plugged in' online. PC Tools Technology. Retrieved on April 15, 2011 from http://www.pctools.com/pressroom/article/id/283/

15. Pinchot, J. L., Paullet, K. L., \& Rota, D. R. (2011). How mobile technology is changing our culture. Journal of Information Systems Applied Research Systems, 4(1), pp. 39-48. 